\title{
Um estrato do perfil das profissionais de TIC na cidade de Maringá-PR
}

\author{
Luciana A. F. Martimiano ${ }^{1}$, Nikaelly V. de Lima ${ }^{2}$, Valéria D. Feltrim ${ }^{1}$, Larissa Roder ${ }^{2}$ \\ ${ }^{1}$ Departamento de Informática - Universidade Estadual de Maringá \\ 87020-900 - Maringá - PR - Brazil \\ ${ }^{2}$ DB1 Global Software \\ 87020-035 - Maringá - PR - Brazil \\ \{lafmartimiano,vdfeltrim\}@uem.br \{nikaelly.lima, larissaroder\}@gmail.com
}

\begin{abstract}
This paper describes an analysis of the professional women profile in the Information and Communication Technology in Maringá-PR. Through a questionnaire answered by 33 professionals, it was possible to identify age, degree of education, the more occupied positions, the perception of gender bias and harassment, and the perception of competence. Establishing a relationship between age and the perception of gender harassment and competence, women over 40 years reported having suffered less harassment and they considered themselves competent. On the other hand, most of the women as young as 39 years old reported having already suffered some kind of harassment and they did not consider themselves competent enough.
\end{abstract}

Resumo. Este artigo apresenta uma análise do perfil das profissionais em Tecnologia da Informação e Comunicação em Maringá-PR. Por meio de um questionário respondido por 33 profissionais, foi possível identificar a idade, o grau de formação, os cargos mais ocupados, a percepção de preconceito de gênero e assédio, e a percepção de competência. Estabelecendo uma relação entre idade e percepção de preconceito e competência, as mulheres com mais de 40 anos relataram ter sofrido menos assédio e preconceito e se consideram competentes. Por outro lado, a maioria das mulheres com até 39 anos relataram já ter sofrido algum tipo de preconceito e que não se consideram competentes o suficiente.

\section{Introdução}

Diversas pesquisas mostram que, atualmente, o número de profissionais do gênero feminino no mercado de trabalho de Tecnologia da Informação e Comunicação (TIC) é pequeno quando comparado ao número de profissionais do gênero masculino [Castro 2013, Leslie et al. 2015, Kenney and Henn 2016, Stout et al. 2016, Keinan 2017]. No entanto, diversas mulheres tiveram e têm uma importante participação no desenvolvimento da área. O primeiro algoritmo, por exemplo, foi especificado em meados de 1800 por Ada Lovelace para a máquina analítica de Charles Babbage. Em meados da década de 1940, a atriz de cinema e inventora Hedwig Eva Maria Kiesler co-desenvolveu o espalhamento espectral por salto de frequência (FHSS) para comunicação sem fio [Ignotofsky 2017].

Com o objetivo de fomentar a discussão sobre a participação das mulheres na área de TIC, este artigo apresenta um estrato do perfil das profissionais da área na cidade de 
Maringá-PR. Um questionário foi aplicado às professoras e analistas do Núcleo de Processamento de Dados (NPD) do campus sede da Universidade Estadual de Maringá (UEM), e com as colaboradoras da empresa DB1 Global Software ${ }^{1}$. A universidade e a empresa foram escolhidas para a realização deste estudo inicial por se tratarem, respectivamente, da maior instituição de ensino superior e da maior empresa de TIC da cidade de Maringá.

Este artigo está organizado da seguinte forma: a Seção 2 descreve o perfil do mercado de TIC em Maringá; a Seção 3 apresenta parte do questionário aplicado e uma análise do perfil das profissionais; por fim, a Seção 4 apresenta as considerações finais.

\section{Mercado de TIC na cidade de Maringá}

$\mathrm{O}$ mercado de TIC tem evoluído rapidamente nos últimos anos em todo o mundo. O movimento das startups e o crescimento das empresas já estabelecidas têm contribuído para essa evolução, fazendo com que a cada dia mais empresas e profissionais participem do ecossistema.

A cidade de Maringá é um importante polo de TIC. Possui uma universidade pública, a UEM, que oferece dois cursos de bacharelado na área, Ciência da Computação e Informática, além de um curso de pós-graduação em nível de mestrado em Ciência da Computação. Possui também instituições de ensino superior privadas que oferecem diversos cursos em nível de graduação e pós-graduação lato sensu relacionados à área. Juntas essas instituições (IES) formam aproximadamente 800 alunos de graduação (modalidade presencial) e 1.200 alunos de pós-graduação (latu sensu e stricto sensu) por ano.

As empresas de TIC da cidade estão organizadas em um Arranjo Produtivo Local (APL) e em uma associação denominada Software by Maringá. Atualmente, há um total de 308 empresas de TIC que empregam 3.072 colaboradores ${ }^{2}$. Diversas ações são realizadas anualmente pelas empresas e pelas IES para fomentar e desenvolver o ecossistema na região.

\section{Perfil das profissionais de TIC em Maringá}

No último evento realizado pela associação das empresas de TIC em 2017, o TICNOVA, houve a participação de 565 pessoas, sendo que apenas 83 eram mulheres (14,7\%). Dos 27 palestrantes, apenas dois eram mulheres $(7,40 \%)$. Em outro evento realizado pelo Departamento de Informática da UEM, dos 44 palestrantes, oito eram mulheres $(18,18 \%)$. Com relação ao número de participantes, havia 283 pessoas, sendo 40 mulheres $(14,13 \%)$.

Como parte de um estudo inicial que busca entender o perfil das profissionais da área, um questionário foi aplicado com as profissionais de TIC da UEM e da DB1 Global Software. As questões do questionário foram definidas pelas autoras deste artigo (com a colaboração de algumas outras pessoas) e enviado via Google Forms para as respondentes $^{3}$. Após o recebimento das respostas, os resultados foram tabulados e analisados conforme descrição a seguir.

Na UEM, do total de 32 professores efetivos, 10 são mulheres $(31,25 \%)$. No NPD, dos 26 analistas, quatro são mulheres (15,38\%). Na empresa, do total de 214 co-

\footnotetext{
${ }^{1}$ https://db1.com.br/

${ }^{2}$ Dados fornecidos pela secretaria da associação que agrega as empresas de TIC.

${ }^{3}$ Questionário disponível em https://goo.gl/forms/TyVvgTVnIWo0PGOk2
} 
laboradores, 37 são mulheres ${ }^{4}(17,29 \%)$. Em termos percentuais, na academia há mais mulheres do que na empresa pesquisada. Um total de 33 mulheres respondeu ao questionário, sendo 13 profissionais da UEM (10 professoras e três analistas do NPD) e 20 da empresa.

Em sua maioria, $81,8 \%$, as profissionais têm formação superior. Destas, 48,5\% têm ensino superior, $27,3 \%$ têm doutorado e $6 \%$ mestrado. As demais ainda estão fazendo curso de graduação. Das profissionais já formadas, 10 (31,3\%) fizeram Ciência da Computação e sete $(21,9 \%)$ Bacharelado em Informática. Considerando o tempo de atuação, $36,4 \%$ têm 16 anos ou mais, e 27,3\% têm entre um e três anos. Com relação à faixa etária, $33,3 \%$ têm mais de 40 anos e $21,2 \%$ têm entre 20 e 25 .

Em 2013, em seu artigo sobre os cargos ocupados na área de TIC pelos profissionais, Kawamoto [Kawamoto 2013] identificou que as mulheres ocupam, nesta ordem, os seguintes cargos: Gerente de Projetos, Analista de Negócios, Outros, Analista de Teste e Qualidade e Analista de Suporte. Em comparação com os dados apresentados por Kawamoto, todos os cargos apontados aparecem nas respostas das entrevistadas. O cargo de Analista de Teste é o segundo mais ocupado pelas entrevistadas, com $25 \%$. Já o cargo de Gerente de Projetos, que é o mais ocupado pelas mulheres na pesquisa de Kawamoto, é ocupado por apenas 3\% das entrevistadas. 10\% das entrevistadas são Analistas de Suporte, enquanto as Analistas de Negócio são 6\%. Como todas as professoras da UEM responderam ao questionário, $28 \%$ das profissionais entrevistadas atuam como Professora/Pesquisadora. A Figura 1 mostra a distribuição dos cargos ocupados pelas respondentes da pesquisa.

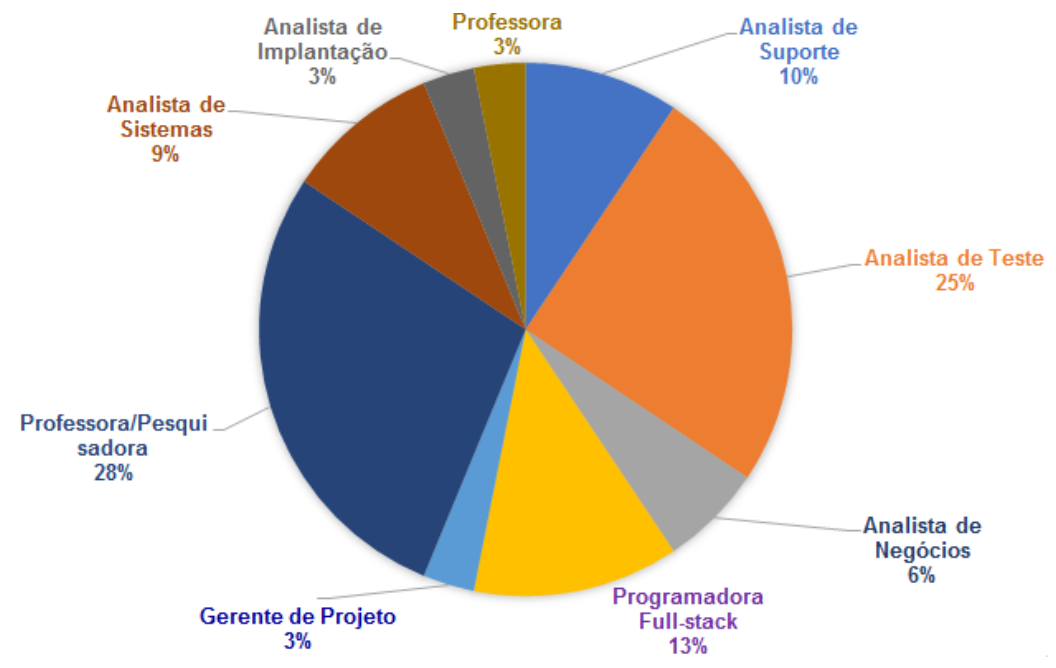

Figure 1. Cargos ocupados pelas profissionais respondentes da pesquisa

Houve um equilíbrio nas respostas considerando as questões sobre assédio e preconceito de gênero. Dezessete $(51,5 \%)$ mulheres responderam que não sofreram assédio, enquanto $16(48,5 \%)$ disseram já terem sofrido algum tipo de assédio. Dezesseis mulheres responderam que já sentiram preconceito de gênero no ambiente de trabalho ou acadêmico, enquanto 17 disseram que não. Dezoito (54,5\%) das 33 mulheres acreditam que já receberam um tratamento diferente por serem do sexo feminino.

\footnotetext{
${ }^{4}$ Dados fornecidos pelo setor de Recursos Humanos da empresa.
} 
A Figura 2 mostra a relação entre idade e percepção de preconceito de gênero. Interessante notar que na faixa etária de 40 anos ou mais, a maioria $(81,8 \%)$ das mulheres respondeu não ter sofrido preconceito. Por outro lado, na faixa etária entre 16 e 39 anos, a maioria $(63,6 \%)$ respondeu ter sofrido preconceito.

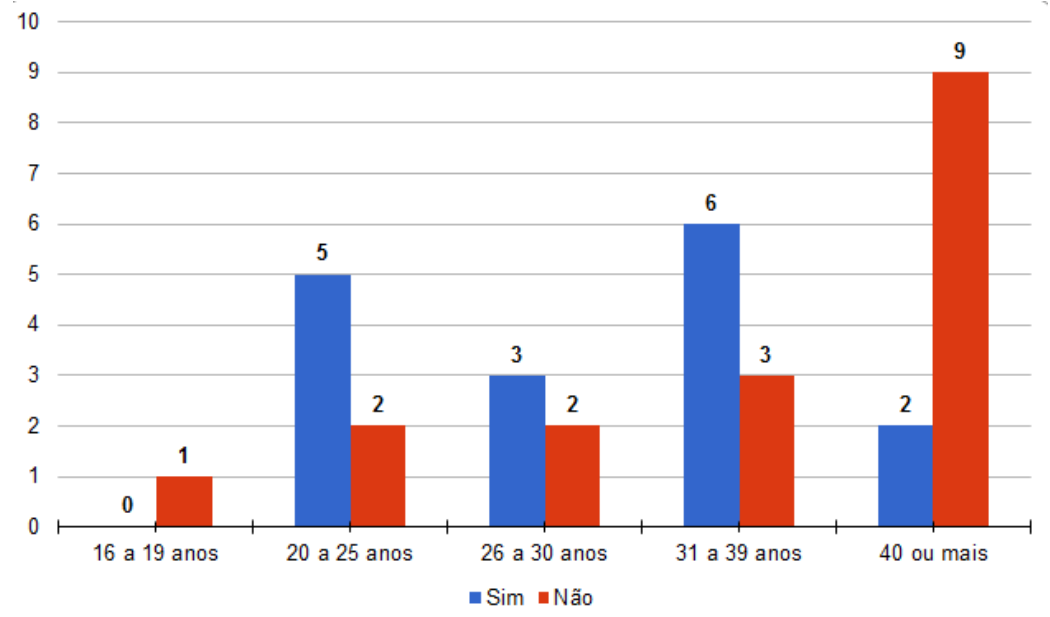

Figure 2. Relação entre idade e percepção de preconceito

A questão sobre a percepção de competência está relacionada com o transtorno chamado "síndrome do impostor". As pessoas que sofrem dessa síndrome mantêm forte consciência de que não são inteligentes, de que estão enganando a todos e que um dia serão descobertas e expostas, conforme descrição de um estudo feito pelas psicólogas Clance e Imes [Clance and Imes 1978]. As psicólogas destacam que as mulheres são àquelas que mais sofrem dessa síndrome.

A Figura 3 mostra a relação entre idade e percepção de competência. Na faixa etária a partir dos 31 anos, 14 (70\%) das 20 mulheres responderam nunca ter deixado de enviar seu currículo por se acharem incompetentes para uma posição de trabalho. Já na faixa dos 16 aos 30 anos, nove $(69,2 \%)$ das 13 mulheres já deixaram de enviar o currículo por não se acharem suficientemente competentes.

Os dois resultados são interessantes no sentido de que mostram que mulheres mais velhas têm uma menor percepção de preconceito de gênero e de uma suposta falta de competência (síndrome do impostor) para atuar na área, enquanto as mulheres mais novas sofrem mais. Uma das explicações pode ser o fato de as mulheres mais velhas iniciaram sua vida acadêmica no início da década de 1990, uma época na qual havia mais mulheres na área. Além disso, pode-se entender que o ambiente acadêmico seja menos preconceituoso, mas não é possível afirmar com certeza a partir dos dados obtidos.

\section{Considerações Finais}

Este artigo apresentou um estrato do perfil das profissionais da área de TIC na cidade de Maringá-PR. Trinta e três mulheres responderam ao questionário. Os dados mostraram que há uma diferença na percepção de preconceito de gênero, de assédio e de competência quando se compara a faixa etária das entrevistadas. Mulheres mais velhas e com mais tempo de atuação relatam ter sofrido menos assédio e preconceito e são mais confiantes em sua capacidade. 


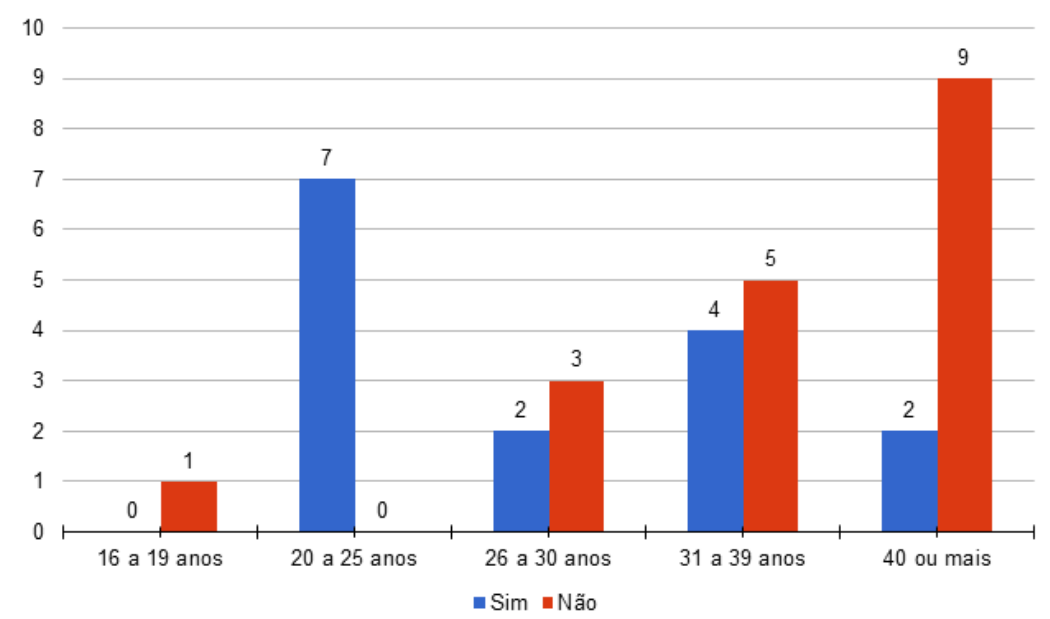

Figure 3. Relação entre idade e percepção de competência

Dando continuidade ao estudo apresentado neste artigo, o questionário será aplicado às outras IES e empresas de TIC da cidade. Assim, será possível ter uma visão mais ampla e detalhada do perfil dessas profissionais.

\section{References}

Castro, B. (2013). The bottlenecks for the entry and permanence of women in the it market in brazil. In XII Conferencia Regional sobre la Mujer de la America Latina y Caribe, page 3. In Portuguese.

Clance, P. R. and Imes, S. A. (1978). The impostor phenomenon in high achieving women: Dynamics and therapeutic intervention. Psychotherapy Theory, Research and Practice, 15(3):241-247.

Ignotofsky, R. (2017). As cientistas: 50 mulheres que mudaram o mundo. Edgard Blucker Ltda, 1st edition.

Kawamoto, D. (2013). Parity for some, but tech women's pay lags overall. http://insights.dice.com/2013/03/22/it-salaries-for-women/.

Keinan, E. (2017). A new frontier: But for whom? an analysis of the micro-computer and women's declining participation in computer science. Master's thesis, Claremont McKenna College.

Kenney, C. and Henn, S. (2016). When women stopped coding. https://www.npr.org/templates/transcript/transcript.php?storyId=487069271.

Leslie, S.-J., Cimpian, A., Meyer, M., and Freeland, E. (2015). Expectations of brilliance underlie gender distributions across academic disciplines. Science, 347(6219):262265.

Stout, J. G., Grunberg, V. A., and Ito, T. A. (2016). Gender roles and stereotypes about science careers help explain women and men's science pursuits. Sex Roles, 75(910):490-499. 